\title{
COMPRESSION PLATE ARTHRODESIS OF THE ELBOW
}

\author{
JOHN A. MCAULIFFE, WILLIAM E. BURKHALTER, \\ E. ANNE OUELLETTE, RONALDO S. CARNEIRO
}

\section{From the University of Miami School of Medicine}

\begin{abstract}
We reviewed 15 patients with an arthrodesis of the elbow using an $\mathrm{AO}$ compression-plate technique, after an average follow-up of $\mathbf{2 4}$ months. The most common indication was an open, infected high-energy injury with associated bone loss.

Arthrodesis was successful in all but one patient in whom severe deep infection necessitated amputation. Eight patients were treated with the metal partly exposed in an infected wound. After removal of the metal, all wounds healed secondarily and none had clinical or radiographic signs of sepsis at latest review.

Compression-plate arthrodesis of the elbow is a generally applicable method that can be used even in cases of severe bone loss. There appears to be greater certainty of union than with other techniques, and no increased risk of subsequent fracture.
\end{abstract}

Arthrodesis of the elbow is rarely indicated and seldom performed: the largest series reported in the English language included 17 patients treated at the Mayo Clinic over more than 40 years (Koch and Lipscomb 1967). Tuberculous arthritis was the most common indication in previously reported series (Hallock 1932; Van Gorder and Chen 1959; Koch and Lipscomb 1967; Arafiles 1981). Other indications have included severe deformity, nonunion or instability after fracture, and old septic arthritis (Staples 1952; Koch and Lipscomb 1967; Rashkoff and Burkhalter 1986).

Arthrodesis of an elbow causes more disability in the use of the hand than any other joint fusion in the arm (Morrey 1988), because loss of elbow movement cannot be compensated for by increased motion at adjacent joints and it is difficult to select an optimal position for fusion (Beckenbaugh 1985; Russell 1987). It is therefore a last resort or salvage procedure when other surgical options are likely to produce complications or failure (Rashkoff and Burkhalter 1986). Younger patients who require good strength and stability of the upper arm may be candidates for this procedure.

The elbow is one of the most difficult joints to fuse surgically (Beckenbaugh 1985; Russell 1987). Most

J. A. McAuliffe, MD, Assistant Professor

W. E. Burkhalter, MD, Professor and Chief of Hand Surgery

E. A. Ouellette, MD, Assistant Professor

R. S. Carneiro, MD, Associate Professor

Department of Orthopaedics and Rehabilitation, University of Miami School of Medicine, PO Box 016960 (D-27), Miami, Florida 33101, USA.

Correspondence should be sent to Dr J. A. McAuliffe.

(C) 1992 British Editorial Society of Bone and Joint Surgery $0301-620 X / 92 / 2305 \$ 2.00$

J Bone Joint Surg [Br] 1992; 74-B:300-4. reports describe new techniques (Hallock 1932; Steindler 1946; Brittain 1952; Staples 1952; Van Gorder and Chen 1959; Müller et al 1979; Arafiles 1981; Rashkoff and Burkhalter 1986): this, as in other surgical fields, indicates that none has been very successful.

When a decision to fuse an elbow has been made, the surgeon requires a reasonable certainty of success. We therefore report a straightforward technique which has been successful in 14 of 15 patients.

\section{PATIENTS AND METHODS}

We reviewed the records and radiographs of 15 patients who had had an arthrodesis of the elbow at the University of Miami/Jackson Memorial Medical Center since 1982. All patients had been followed up at least to radiographic union and complete wound healing over five to 54 months (mean 24).

There were 11 men and four women with an average age of 44 years (18 to 68). The most common indication in ten patients was a severe open intra-articular fracture with loss of bone and soft tissue (Fig. 1). Three patients had the sequelae of septic arthritis, one of them with active sepsis of a total elbow allograft in situ for about five years. One patient had nonunion of a distal humeral fracture with severe arthritis and instability, and one spastic patient had an open, unstable elbow after the surgical release of a joint contracture.

Five of the open fractures were caused by gunshot wounds and the other five by high-energy trauma in motor-vehicle and industrial accidents. Nine of these ten patients had an associated nerve injury, with two nerves involved in five. One patient had vascular problems after an arterial injury and two had other fractures of the same arm. 


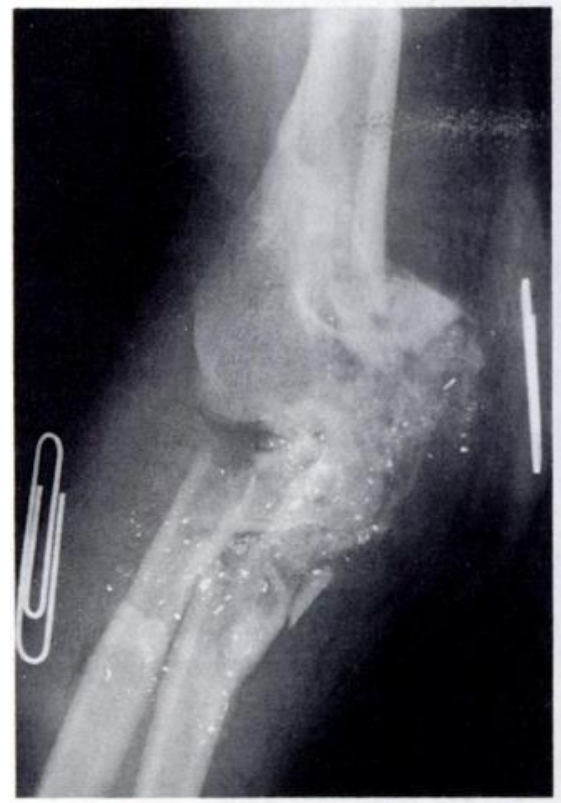

Fig. 1a

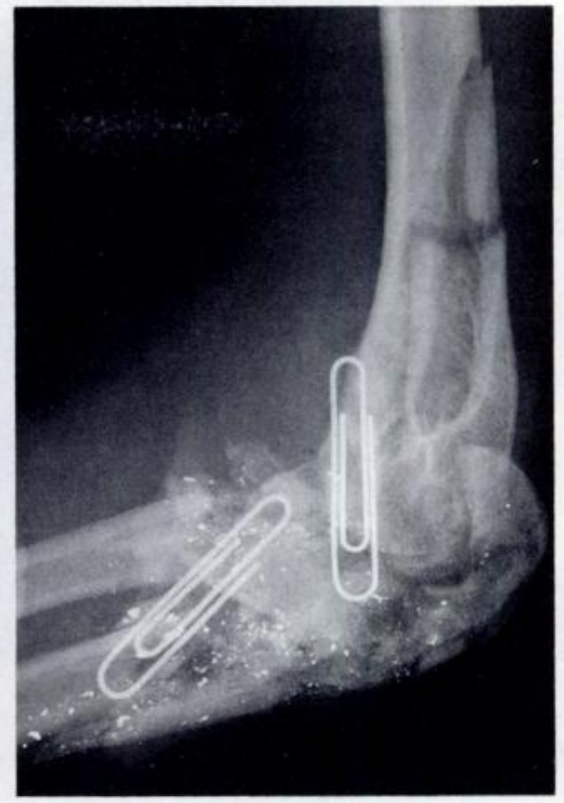

Fig. 1b

Radiographs of a complicated open fracture caused by a gunshot wound. There is severe comminution and some loss of bone.

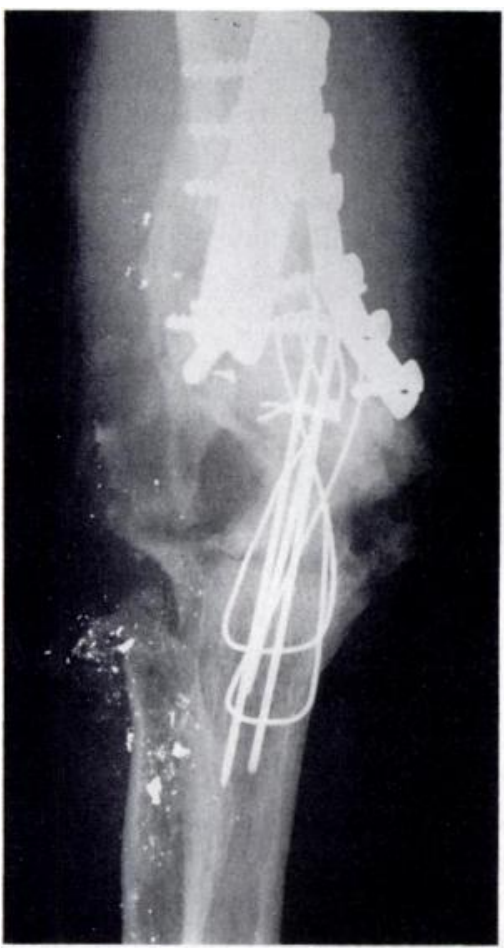

Fig. 2

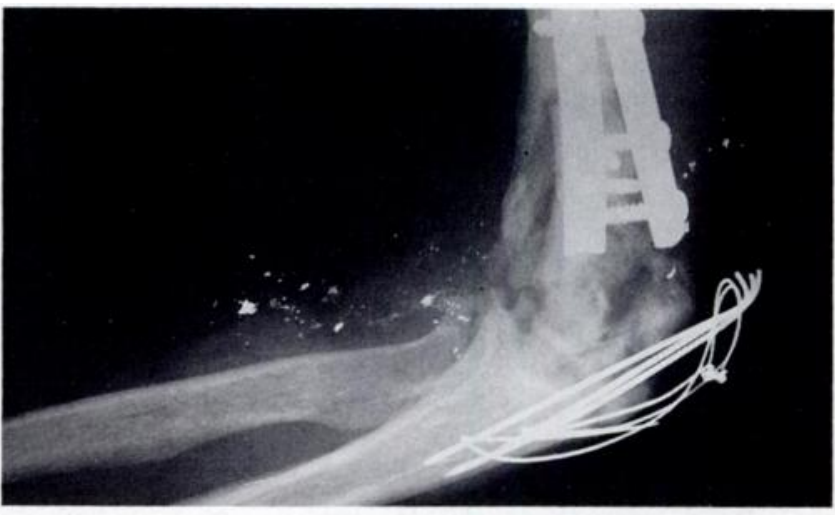

Radiographs of an elbow which became infected after the internal fixation of a fracture. There is destruction of the articular surfaces.
Eight patients had undergone an average of 4.5 surgical procedures before arthrodesis (range 2 to 10) in attempts to close wounds, eradicate infection, or fix fractures (Fig. 2). In two patients, treated primarily at our institution, there had been only one operation for irrigation and debridement, fusion being planned at the time of presentation.
The eight open fractures not treated primarily were all infected and had positive cultures at the time of arthrodesis. Seven of these patients and one with active septic arthritis following arthroplasty had no attempt at wound closure following fusion. In five patients, meshed split-thickness skin grafts were applied to exposed muscle and no particular effort was made to cover the metal 


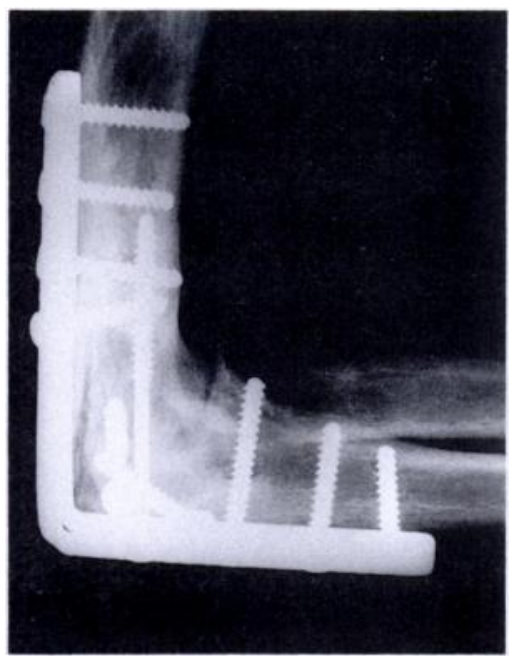

Fig. 3a

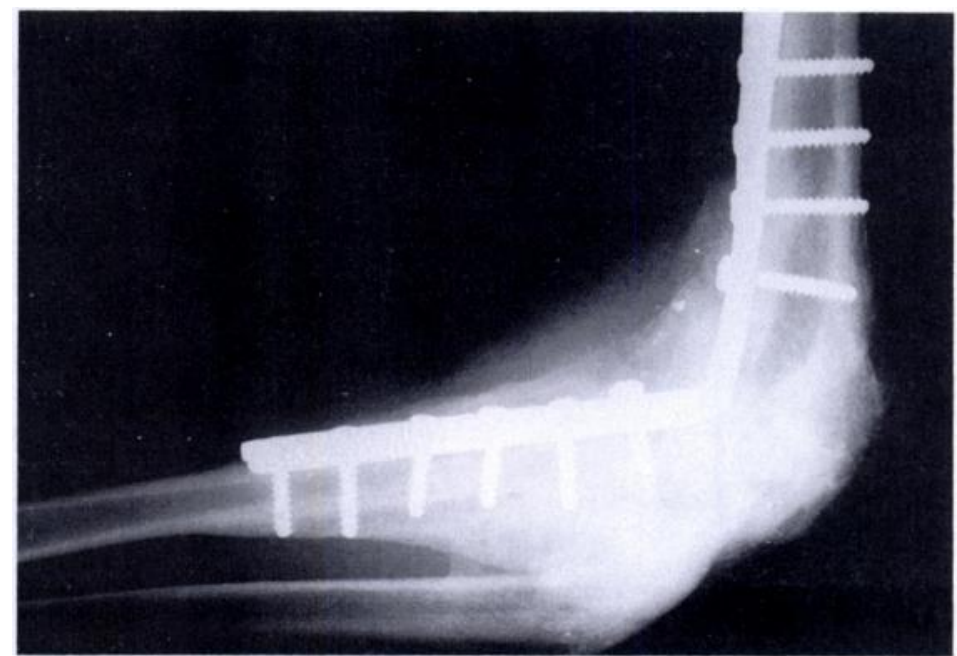

Fig. 3b

Lateral radiographs of healed posterior humero-ulnar (a) and anterior humero-radial (b) arthrodesis, before the removal of metal.

fixation. Wound closure with a free flap was attempted in one patient within one week of injury but resulted in fulminant deep sepsis necessitating transhumeral amputation. Four patients with active infection and with a pure growth of staphylococci at the time of arthrodesis had intravenous antibiotics for two to four weeks, and five with Gram-negative infection had antibiotic treatment for six weeks.

Posterior humero-ulnar fixation was used in 12 cases and an anterior humeroradial technique in three, with iliac-crest bone grafting in all. In three of the 15 patients, bone grafting was delayed because of concern regarding the adequacy of wound excision. This was performed at the time of secondary soft-tissue debridement, from one to four weeks later.

All but two elbows were fused in $90^{\circ}$ to $100^{\circ}$ flexion. The others, in non-dominant arms, were fused at $45^{\circ}$ to be more useful in assisting other activities. External immobilisation was rarely used postoperatively.

Operative technique. We use a single AO dynamic compression plate in all cases, placing it either posteriorly or anteriorly (Fig. 3) according to the location of softtissue injury and available bone stock. Posterior plates are applied via a long posteromedial incision, the ulnar nerve being isolated, protected and usually transposed anteriorly. Henry's (1970) approach is used anteriorly with isolation of the radial nerve. We prefer this approach when humeroradial fixation is planned.

Devitalised and infected bone and soft tissue are excised and synovectomy is performed. The radial head is excised when humero-ulnar fixation is planned and two flat cancellous surfaces are created for coaptation at the desired angle of arthrodesis. One or two lag screws are then directed obliquely across the arthrodesis site to provide compression, taking care that they do not interfere with later placement of the plate.
When possible, we prefer to use a broad $4.5 \mathrm{~mm}$ plate, but in smaller patients a narrow plate may be necessary. We aim to use four screws in each of the proximal and distal bones, and this usually requires a 12hole plate. The plate is contoured to fit and then applied in the neutralisation mode. If lag screws are not previously placed the AO tension device may be used. Adjacent cortical surfaces are roughened with an osteotome and iliac-crest bone graft is added. Neurolysis, nerve repair or grafting, and skin grafting are performed as required during the same operation.

\section{RESULTS}

Successful arthrodesis was achieved in 14 patients (93\%) in an average period of six months. The single failure occurred in the patient with arterial injury; after freeflap coverage, deep sepsis and the onset of gangrene necessitated transhumeral amputation.

Solid radiographic union with cross-trabeculation was delayed for over six months (six to 20) in four patients, two of whom required repeat bone grafting. Another patient who had a block-shaped cancellous bone graft interposed in an attempt to maintain length had prolonged wound drainage and extrusion of the graft. The interposed bone graft was removed and revision plating with direct apposition of the bone ends resulted in union within four months. There were no failures of fixation.

Eight patients were treated with some metal exposed, until it was removed after four to 21 months. All four patients with delayed union were in this group, but they all had appreciable loss of bone and active infection; the effect of open treatment on delay to union was therefore uncertain. All wounds healed secondarily after the removal of metal, and no patient had clinical or 


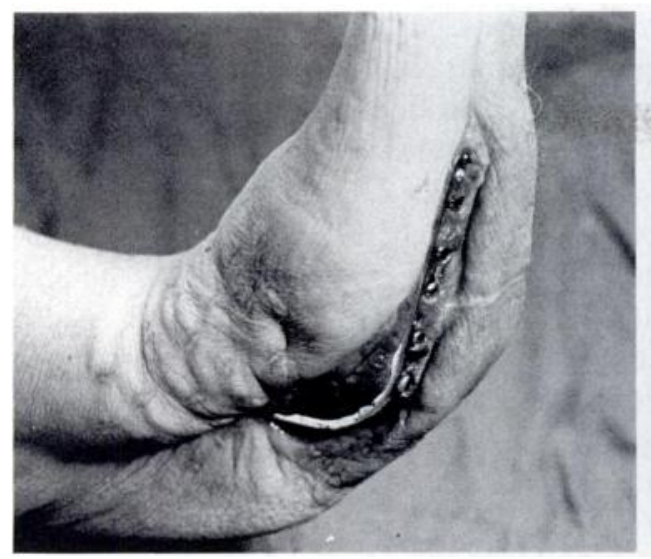

Fig. 4a

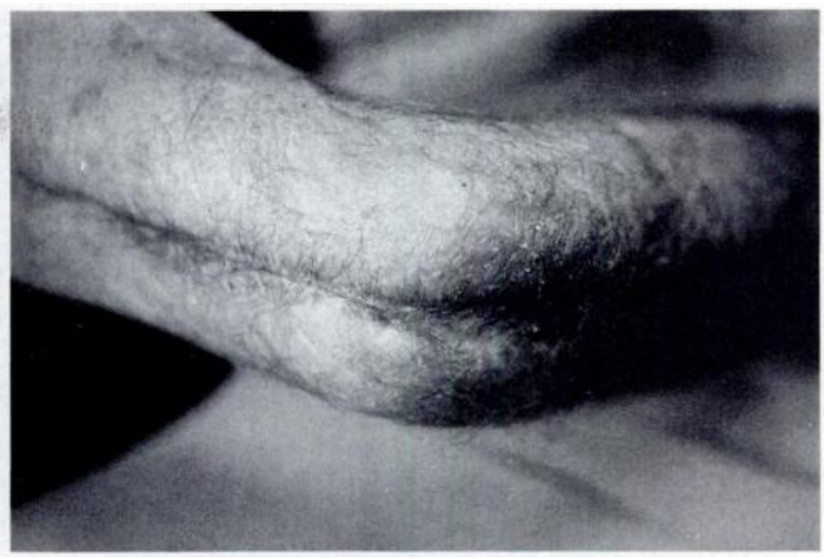

Fig. 4b

Figure $4 \mathrm{a}$ - Open treatment of an infected wound at three months with the plate exposed. Figure $4 \mathrm{~b}-$ Final result after removal of metal.

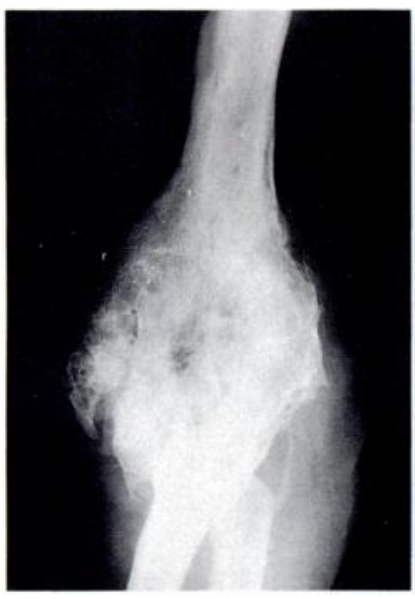

Fig. 5a

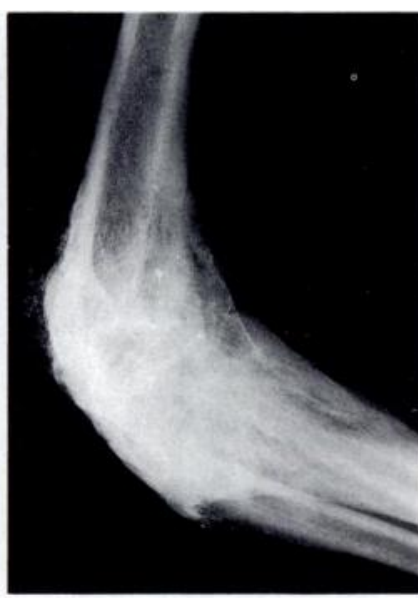

Fig. 5b
Anteroposterior and lateral radiographs of a healed elbow arthrodesis showing radio-ulnar synostosis.

radiographic signs of sepsis at latest follow-up (Fig. 4). Two patients have required revision of deeply adherent scars; local soft-tissue expansion gave excellent results and no infective complications.

Two patients sustained fractures of forearm bones after arthrodesis. One, at one month, was through a previous external fixation pin site just distal to the fusion plate; the other was through the most distal screw hole of the plate, two years after fusion. Both fractures were treated by open reduction and internal fixation and healed within three months. Despite excision of the radial head in all humero-ulnar fusions, the proximal radius became incorporated into the fusion mass with loss of forearm rotation in eight of the 11 cases (Fig. 5).

Function after elbow arthrodesis is difficult to assess, especially if there are associated nerve injuries. The most obvious loss of function in limbs with combined injuries is usually due to the neurological deficit. All of our patients who had an elbow arthrodesis on an 'elective' basis felt that function had improved and that they had greater strength: none wished to return to the preoperative status. Only one patient complained of pain; this was associated with neuromas of the major nerves at the level of the elbow.

\section{DISCUSSION}

Although elbow arthrodesis is an uncommon procedure, numerous techniques have been described. Earlier reports were mainly concerned with tuberculous arthritis, and methods included the ingenious use of local and distant bone grafts (Hallock 1932; Steindler 1946; Brittain 1952; Van Gorder and Chen 1959; Koch and Lipscomb 1967). External fixation has been advocated before, especially by the AO group (Müller et al 1979). Four successful cases after compression plating have been described (Russell 1987), and we have previously reported seven such cases (Rashkoff and Burkhalter 1986).

Fusion of the elbow is difficult to achieve; success rates of $36 \%$ in cases of tuberculous arthritis and $67 \%$ for other indications were reported by Koch and Lipscomb (1967). Chemotherapy has improved the fusion rate for tuberculous arthritis, and Arafiles (1981) has reported a technique that was successful in all 11 of his patients. His series is the only other report with a reasonable success rate, but we feel that compression plating is more generally applicable. Where there is appreciable bone loss or deformity, the interlocking segments of bone suggested by Arafiles could not be created. Compression plating provides more rigidity and eliminates the need for external immobilisation.

The long-lever arm created by elbow fusion is cited not only to explain the difficulties in achieving arthrodesis, but also as a cause of high rates of fracture after fusion (Beckenbaugh 1985). Koch and Lipscomb (1967) 
reported such fractures in almost one-quarter of their patients. Our rate compares favourably, and one of our two fractures could probably have been prevented by extending the plate beyond the previous pin site. Recent reports of fracture after the removal of plates from the forearm give concern (Hidaka and Gustilo 1984; DeLuca, Lindsey and Ruwe 1988), but this risk seems to lessen after four months; most of our patients have had their plates removed for longer than this.

Any position for fusion will eliminate the performance of some activities (Morrey et al 1981; Morrey 1988). Most authors recommend $90^{\circ}$ of flexion, but positions from $45^{\circ}$ to $110^{\circ}$ of flexion have been suggested (Snider and DeWitt 1973; Beckenbaugh 1985; Russell 1987). The decision will depend upon whether working activities or self-care are the functional goal, and on the mobility of the contralateral elbow. It has been suggested that $90^{\circ}$ is favourable for providing maximal strength in the hand (Mathiowetz, Rennells and Donahoe 1985). Most of our arthrodeses were almost at $90^{\circ}$ of flexion, but we have become increasingly aware that for maximum use and for appearance fusion nearer $45^{\circ}$ is probably preferable.

Exuberant callus and heterotopic ossification after major trauma may help to achieve arthrodesis, but its influence on radio-ulnar synostosis is certainly not beneficial. Loss of forearm rotation should be anticipated to avoid ankylosis in an undesirable position. We generally prefer a position of $10^{\circ}$ to $20^{\circ}$ supination; this enables a neurologically impaired patient to view the working surface of his hand. Abduction of the shoulder can provide some functional pronation for these patients.

The use of internal fixation in the presence of active infection is controversial, but we have experienced few major complications or limitations. At the elbow, plate fixation is simpler and less risky to neurovascular structures than the application of a rigid quadrilateral external fixator. Wound care and dressing changes are easily performed and the rigidity of plate fixation facilitates early and active rehabilitation of the shoulder, wrist and hand.

We had few difficulties arising from the presence of exposed metal while fusion progressed, and there was prompt healing by secondary intention after the plate and screws had been removed. Skeletal stability had a beneficial effect on wound control and eradication of infection (Calkins, Burkhalter and Reyes 1987).

Although the indications for elbow fusion are rare, there are few reasonable alternatives in the presence of sepsis and instability. Compression-plate arthrodesis is a reliable, safe and simple technique for the salvage of such cases, and allows effective management of infections and soft-tissue complications.

No benefits in any form have been received or will be received from a commercial party related directly or indirectly to the subject of this article.

\section{REFERENCES}

Arafiles RP. A new technique of fusion for tuberculous arthritis of the elbow. J Bone Joint Surg [Am] 1981; 63-A:1396-400.

Beckenbaugh RD. Arthrodesis. In: Morrey BF, ed. The elbow and its disorders. Philadelphia, etc: W. B. Saunders, 1985:582-8.

Brittain HA. Architectural principles in arthrodesis. Second ed. Edinburgh: E \& S Livingstone, 1952:161-7.

Calkins MS, Burkhalter WE, Reyes F. Traumatic segmental bone defects in the upper extremity: treatment with exposed grafts of corticocancellous bone. J Bone Joint Surg [Am] 1987; 69-A: 19-27.

DeLuca PA, Lindsey RW, Ruwe PA. Refracture of bones of the forearm after the removal of compression plates. J Bone Joint Surg [Am] $1988 ; 70-A: 1372-6$.

Hallock H. Fusion of the elbow joint for tuberculosis. J Bone Joint Surg $1932 ; 14: 145-53$.

Henry AK. Extensile exposure. Second ed. Edinburgh: Churchill Livingstone, 1970:90-111.

Hidaka S, Gustilo RB. Refracture of bones of the forearm after plate removal. J Bone Joint Surg [Am] 1984; 66-A :1241-3.

Koch M, Lipscomb PR. Arthrodesis of the elbow. Clin Orthop 1967; $50: 151-7$.

Mathiowetz V, Rennells C, Donahoe L. Effect of elbow position on grip and key pinch strength. $J$ Hand Surg [ Am] 1985; 10-A :694-7.
Morrey BF. Elbow reconstructive surgery. In: Chapman MW, ed. Operative orthopaedics. Vol I. Philadelphia: JB Lippincott, 1988:789-805.

Morrey BF, Askew LJ, An KN, Chao EY. A biomechanical study of normal functional elbow motion.J Bone Joint Surg [ Am] 1981 ; 63A:872-7.

Müller ME, Allgöwer M, Schneider R, Willenegger H. Manual of internal fixation: techniques recommended by the AO Group. Second ed. Berlin, etc: Springer-Verlag, 1979.

Rashkoff E, Burkhalter WE. Arthrodesis of the salvage elbow. Orthopaedics 1986; 9:733-8.

Russell TA. Arthrodesis of upper extremity. In: Crenshaw AH, ed. Campbell's operative orthopaedics. Seventh ed. Vol 2. St. Louis, etc: CV Mosby Co, 1987:1131-42.

Snider WJ, DeWitt HJ. Functional study for optimum position for elbow arthrodesis or ankylosis. J Bone Joint Surg [Am] 1973; 55A:1305.

Staples OS. Arthrodesis of the elbow joint. J Bone Joint Surg [Am] 1952; 34-A:207-10.

Steindler A. The traumatic deformities and disabilities of the upper extremity. Springfield, Illinois: Charles C. Thomas, 1946:274-8.

Van Gorder GW, Chen $C$. The central-graft operation for fusion of tuberculous knees, ankles and elbows. J Bone Joint Surg [Am] $1959 ; 41-A: 1029-46$. 